\title{
High-Intensity Airborne CMUT Transmitter Array With Beam Steering
}

\author{
Talha Masood Khan ${ }^{\circledR}$, Student Member, IEEE, Akif Sinan Taşdelen, Mehmet Yilmaz ${ }^{\circledR}$, \\ Abdullah Atalar ${ }^{\circledR}$, Fellow, IEEE, and Hayrettin Köymen ${ }^{\circledR}$, Senior Member, IEEE
}

\begin{abstract}
A $2 \times 2$ high-intensity CMUT transmit array that is capable of two-dimensional beam steering is presented. The device uses an ac drive voltage at half the ultrasound frequency without any dc bias, enabling the usage of the entire gap height. The device is designed using a large signal equivalent model approach. A fabrication method that requires a single lithographic mask has been used. The fabricated devices are operated at $76 \mathrm{kHz}$ to beam steer at various angles. An equivalent element pressure of $144 \mathrm{~dB} / / 20 \mu \mathrm{Pa}$ at the transducer surface was measured. The entire half-space can be steered without any sidelobes and the beam obtained from the array is in excellent agreement with the theoretical predictions.

[2020-0253]
\end{abstract}

Index Terms-Airborne ultrasound, beam steering, CMUT, high intensity, transducer array, unbiased CMUT.

\section{INTRODUCTION}

A RRAYS in ultrasonic technology have been used due to their ability of electronic beam forming and steering at varying angles or depths. Ultrasonics in air provides a challenge in implementation because of high acoustic impedance mismatch and high attenuation. Capacitive micromachined ultrasonic transducers (CMUTs) are now technologically advanced to compete commercially with available piezoelectric ultrasonic transducers in applications requiring high acoustic intensity.

Novel ferro-electric materials and fabrication methodologies provide phased array applications with a pressure of $102 \mathrm{~dB} @ 0.2 \mathrm{~m}$ (All dB values in this work are referenced to $20 \mu \mathrm{Pa} \mathrm{rms}$ ) at $100 \mathrm{kHz}$ using focused beamformed 32 elements linear array [1]. A 1-dimensional, 8-element flextensional ultrasonic transducer array operated at $30 \mathrm{kHz}$

Manuscript received June 26, 2020; revised September 2, 2020; accepted September 19, 2020. Date of publication October 2, 2020; date of current version December 1, 2020. Subject Editor L. Buchaillot. (Corresponding author: Talha Masood Khan.)

Talha Masood Khan and Mehmet Yilmaz are with the Institute of Materials Science and Nanotechnology, Bilkent University, 06800 Ankara, Turkey, and also with the National Nanotechnology Research Center (UNAM), Bilkent University, 06800 Ankara, Turkey (e-mail: talha.khan@bilkent.edu.tr).

Akif Sinan Taşdelen is with the Bilkent University Acoustic and Underwater Technologies Research Center (BASTA), Bilkent University, 06800 Ankara, Turkey.

Abdullah Atalar and Hayrettin Köymen are with the National Nanotechnology Research Center (UNAM), Bilkent University Acoustic and Underwater Technologies Research Center (BASTA), Bilkent University, 06800 Ankara, Turkey, and also with the Department of Electrical and Electronics Engineering, Bilkent University, 06800 Ankara, Turkey.

Color versions of one or more of the figures in this article are available online at https://ieeexplore.ieee.org.

Digital Object Identifier 10.1109/JMEMS.2020.3026094 shows a phased array performance of $132 \mathrm{~dB} @ 0.3 \mathrm{~m}$ and $123 \mathrm{~dB} @ 1 \mathrm{~m}$ measured in the far field [2].

Airborne ultrasonic arrays are designed for two purposes: (i) as phased arrays to obtain a steered beam of sound in the far field, and (ii) to obtain a high ultrasonic intensity either to be exploited in the near field of the array or a fixed narrow beam. The element size in phased arrays must be small enough, compared to the wavelength of sound, so that the beam is steered in the space without limitations and sidelobes, whereas the latter can be implemented with larger element apertures.

CMUTs in airborne mode have been used for various applications [3]-[13]. Several works have been focused on highintensity directional ultrasound [14]-[17]. Currently, airborne ultrasonic devices are being used for ranging, wind sensing, gesture sensing, as well as obstacle sensing in smart cars and tactile displays [18]-[21]. There are phased array systems for narrowband airborne ultrasonic transmission that provide the capability of cascading several elements together for acoustic levitation, parametric loudspeaker, standing wave levitation, gravimetric sensor, fingerprint sensor, and ultrasonic haptic feedback [22]-[26].

All the reported arrays have different operating frequencies, relative sizes with respect to wavelength, beam-steering capabilities and employed technologies, which makes it difficult to make direct comparisons. The output pressure levels can be compared in terms of respective estimated pressure at the surface of the array [17] since the far field pressure is affected by the Rayleigh distance and beamwidth. For the array in [1], it is understood that array surface pressure is low, although $102 \mathrm{~dB}$ is obtained at $20 \mathrm{~cm}$ focus distance by beamforming 32 elements. The pressure at the surface of the array in [2] is estimated to be about 140-145 dB from the reported far field pressure levels.

Although CMUT transducers provide attractive features, they suffer from limited transmitted pressure when driven using $d c$ voltage bias, due to collapse phenomena and the associated choice of membrane dimensions and gaps [27]. To overcome this constraint, in one study, piezo-transmitters and CMUT receivers have been successfully fabricated together that improve the transmit range and axial resolution of the system [28]. A CMUT design with an embossed pattern has been fabricated to improve output pressure in a liquid medium [29].

A large, 100-mm diameter, CMUT transmitter array generating a high transmitted pressure $107 \mathrm{~dB} @ 3 \mathrm{~m}(135 \mathrm{~dB}$ 
referred to the surface) at $50 \mathrm{kHz}$, when biased at $380 V_{d c}$ and driven using $200 V_{a c}$, has been reported for parametric array operation [17]. Airborne ultrasonic imaging based on the synthetic aperture technique that replaces the phased array by mechanically moving the elements is also reported [30].

In this work, we present design, production, and operation of a half-frequency driven unbiased CMUT array capable of beam steering at high intensity. When a $d c$ bias is applied, the plate is depressed further at smaller drive levels and can collapse before it can reach the full swing. We demonstrate, both analytically and experimentally that an airborne CMUT transmitter array can be optimally designed to provide beam steering while providing a high output pressure normalized to the surface. The general physical requirements, such as element size and spacing, for better performance, is a wellstudied topic. The elastically linear operation requirement for CMUTs, however, imposes limitations on the element size [31].

Lumped element equivalent circuit-based model [32] was exploited to derive a CMUT transmitter array operated at zero bias. It is shown in [33] that very high radiated pressure can be obtained from a CMUT if it is driven unbiased, where the radiation plate vibration can span the entire gap height without collapsing.

In [34], the unbiased array operation is demonstrated by implementing beamforming and steering using appropriate phasing at half the frequency of transmission. The elements of the array are driven within the elastically linear range, where the generated acoustic intensity is low.

In this work, we extend the array operation to very highintensity transmission, where both beamforming and steering are done up to $144 \mathrm{~dB}$ surface pressure levels. It is shown that the required phasing for linear operation remains the same at the highest intensity level, although the dynamics of the radiation plates are no longer elastically linear. We report a design methodology for arrays that have very high-power transmission performance.

Fabrication inaccuracies such as a change in radius, plate thickness, or gap height may lead to discrepancies in frequency response and radiated pressures. On the other hand, the beamsteering fundamentally requires all elements in an array to perform similarly. In this paper, we show that beam steering can be achieved in the entire range by amplitude and phase compensation, despite these inaccuracies. We used our models to account for these deviations and henceforth demonstrate the optimally compensated beam steered CMUT array. Circuit model findings were verified using a set of measurements on several CMUT elements and arrays.

\section{CMUT Cell Design}

A CMUT transducer array can be designed and optimized using both finite element analysis (FEA) and equivalent circuit modeling. Using equivalent circuit models together with self and mutual radiation impedance yields accurate results which compare well with measurements even in large-signal airborne applications [32]-[36]. The equivalent circuit based approach provides an advantage over the FEA when simulating arrays with multiple cells and elements [37].

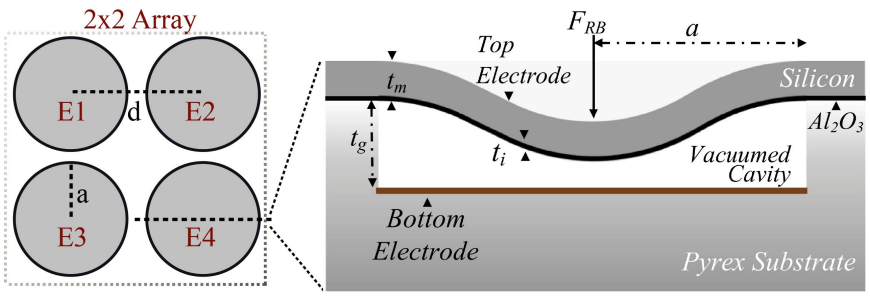

Fig. 1. A cross-section of a single element in a $2 \times 2$ CMUT array.

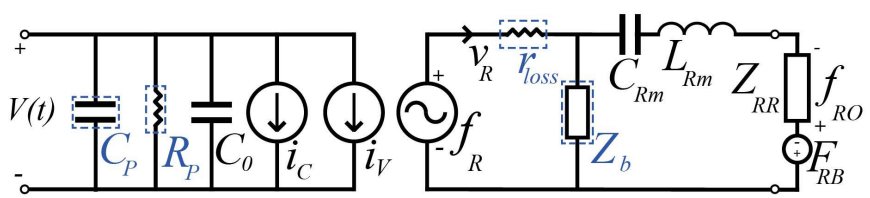

Fig. 2. A large-signal equivalent circuit model using spatial rms quantities for a single CMUT element.

\section{A. Single Cell Design}

Fig. 1 shows a cross-sectional view of a typical CMUT element. Here, $a$ denotes the radius of the radiation plate, $t_{g}$ is the gap height between the radiation plate and bottom electrode, $t_{i}$ denotes the thickness of the insulator layer, $t_{m}$ is the thickness of the plate and $F_{R B}$ denotes the static force being exerted on the plate. An acoustic wave can be generated in a CMUT element by applying an electrical voltage between the two electrodes.

The $d c$ operation of a CMUT puts a limit on the amount of plate swing achievable for a given gap. With a $d c$ bias, the plate is depressed at no excitation and the collapse phenomenon limits the swing amplitude. Consequently, only a portion of the available gap height can be utilized for plate swing in biased operation. The unbiased $a c$ operation of the CMUT employs the terminal voltage at half the desired radial frequency, $\omega$, given as [33], [38]

$$
V(t)=V_{m} \cos \left(\frac{\omega}{2} t\right)
$$

Since the transduction force is proportional to the square of the potential difference between the terminals, the dynamic force on the plate is at the desired radial frequency $\omega$.

The large-signal equivalent circuit model [32] shown in Fig. 2 assumes that the plate is rigidly clamped over the edges. The left-hand side of the equivalent circuit represents the electrical side of the circuit, with $C_{o}$ being the capacitance of the undeflected plate. $i_{C}$ represents the additional current when the capacitor value is changed because of deflection. $i_{V}$ is the current arising from the velocity in the mechanical side. The right-hand side is the mechanical section, with $C_{R m}$ and $L_{R m}$ representing plate compliance and mass of the plate respectively. $v_{R}$ is spatial rms particle velocity and $f_{R}$ is a nonlinear voltage-controlled voltage source generating the transduction force. $Z_{R R}$ is the radiation impedance at the acoustic port. $f_{R O}$ is the transmitted force generated at the acoustic terminal while $F_{R B}$ is the force caused by the static ambient pressure. The model includes the effects of dielectric loss $\left(R_{P}\right)$ and the frictional loss $\left(r_{\text {loss }}\right)$ and the 
loss to backing impedance $\left(Z_{b}\right)$ [33], [39]. $C_{P}$ stands for the parasitic capacitance of the cell.

A thin clamped plate displacement profile is given as [40],

$$
x(r, t)=x_{p}(t)\left(1-\frac{r^{2}}{a^{2}}\right)^{2} \text { for } \mathrm{r} \leq \mathrm{a}
$$

when a uniformly distributed force acts on its surface. Here $r$ is the radial position and $x_{p}$ is the center displacement of the plate towards the gap. This profile function is maintained as long as the plate deflection is low and the vibration is elastically linear. As the deflection amplitude increased, the profile gradually deviates from (2). It is accepted that the plate motion is in elastic linear range if the center displacement is less than $20 \%$ of the thickness of the plate [41].

It is shown in [31] that CMUT resonance remains in the vicinity of the mechanical resonance frequency determined by $C_{R m}$ and $L_{R m}$, when driven unbiased. This resonance frequency prevails even at very high dynamic displacement amplitudes, as long as the static center deflection of the plate due to atmospheric pressure is within the linear elastic range. Duffing effect [42] on the resonance frequency due to the stiffening of plate material is overwhelmed by the increased nonlinearity in the dynamic transduction force when the vibration amplitude spans the entire gap.

The quality factor of the mechanical section, $Q_{m}$, for a single lossless CMUT element is given as

$$
Q_{m}=\frac{\omega_{r} L_{R m}+X_{R R}\left(k_{r} a\right)}{R_{R R}\left(k_{r} a\right)}=\frac{k_{r} a}{R_{1}\left(k_{r} a\right)} \frac{t_{m}}{a} \frac{\rho_{m}}{\rho_{0}}+\frac{X_{1}\left(k_{r} a\right)}{R_{1}\left(k_{r} a\right)}
$$

where $t_{m} / a$ is obtained from the resonance condition as,

$$
\frac{t_{m}}{a}=\left(k_{r} a\right) c_{0} \sqrt{\frac{9\left(1-\sigma^{2}\right) \rho_{m}}{80 Y_{0}}}
$$

in terms of velocity of sound in air, $c_{0}$, and the material properties. Here, $k_{r}=2 \pi / \lambda$, is the wavenumber in air at the resonance frequency, $f_{r}$, and $\rho_{m} / \rho_{0}$ is the density ratio of plate material to air. $R_{1}$ and $X_{1}$ are the normalized real and imaginary parts of the radiation impedance, $R_{R R}\left(k_{r} a\right)+$ $j X_{R R}\left(k_{r} a\right)$, of the transducer, respectively. $Y_{0}$ and $\sigma$ are the Young's modulus and Poisson's ratio of the radiation plate, respectively.

For a silicon plate, (3) predicts a minimum quality factor at $k_{r} a \approx 0.5$, where the transducer bandwidth is maximum. This value is not usable, since the corresponding $a / t_{m}$ ratio found from (4) is very large (> 130), requiring a very thin plate. Such thin plates suffer stiffening in CMUTs with a vacuum gap when subjected to atmospheric pressure. Geometrical elastic nonlinearity occurs due to excessive static center displacement. In [43], it is shown that the maximum $a / t_{m}$ ratio that a silicon plate can have is about 35 for entirely linear (elastic) operation in air when no bias is applied. $a / t_{m}<35$ corresponds to $k_{r} a>1.95$ for a silicon plate.

In order to sample the entire Fourier half-space unambiguously, the center-to-center inter-element spacing must be less than half a wavelength [16], [44]. This requires $k_{r} a<1.57$. If the element size is larger and consequently the spacing is more than half a wavelength, the grating lobes of the array
TABLE I

Material Properties ANd Dimensions

\begin{tabular}{lccc}
\hline \hline Physical Property & Symbol & Value & Units \\
\hline Young's Modulus $(\mathrm{Si})$ & $Y_{0}$ & 148 & $\mathrm{GPa}$ \\
Poisson's Ratio (Si) & $\sigma$ & 0.17 & \\
Density (Si) & $\rho_{m}$ & 2370 & $\mathrm{~kg} / \mathrm{m}^{3}$ \\
Dielectric constant $\left(\mathrm{Al}_{2} \mathrm{O}_{3}\right)$ & $\varepsilon_{r}$ & 9.7 & \\
Plate Thickness $(\mathrm{Si})$ & $t_{m}$ & 40 & $\mu \mathrm{m}$ \\
Insulator Thickness $\left(\mathrm{Al}_{2} \mathrm{O}_{3}\right)$ & $t_{i}$ & 100 & $\mathrm{~nm}$ \\
Gap Height & $t_{g}$ & 10 & $\mu \mathrm{m}$ \\
Plate Radius & $a$ & 1.4 & $\mathrm{~mm}$ \\
Center-to-center Element Pitch & $d$ & 3 & $\mathrm{~mm}$ \\
\hline \hline
\end{tabular}

emerges and gradually become larger [45], [46]. This effect is very significant if the spacing is close to a wavelength. However, grating lobes remain small, comparable to sidelobe levels, for element spacing up to about $90 \%$ of the wavelength. Often, arrays are steered in a smaller sector such as $-\pi / 3$ to $+\pi / 3$ rather than the entire half space, $-\pi / 2 t o+\pi / 2$, in which case the element spacing can be larger for unambiguous steering performance within the sector [46]. Considering both of these issues, designing an array having elements with $k_{r} a \approx 2$ secures elastic linear operation for low amplitude vibrations and the resulting element spacing of $65 \%$ of a wavelength maintains beam steering in a large sector.

Most of the airborne ultrasonic arrays operate between 30-100 kHz. We designed our CMUT cells to operate in $70-80 \mathrm{kHz}$ band. The attenuation in air is slightly more than $2.2 \mathrm{~dB} / \mathrm{m}$ at this frequency and at SAP (Standard Atmospheric Pressure, $101 \mathrm{kPa}$ ) and $20^{\circ} \mathrm{C}$ [47].

For a silicon plate with $k_{r} a \approx 2.0$ and $a / t_{m} \approx 35$, a mechanical resonance frequency of about $77.6 \mathrm{kHz}$ is obtained by $t_{m}=40 \mu \mathrm{m}$ and $a=1.4 \mathrm{~mm}$ using,

$$
\omega_{r}=\frac{t_{m}}{a^{2}} \sqrt{\frac{80 Y_{o}}{9\left(1-\sigma^{2}\right) \rho_{m}}}
$$

With these dimensions, using the material properties given in Table I, the center deflection due to atmospheric pressure $\left(X_{p}\right)$ must be less than $8 \mu \mathrm{m}$ so that elastic linearity is maintained [41], i.e., $X_{P} / t_{m}<0.2$.

For $X_{p}=6.8 \mu \mathrm{m}$ at ambient pressure, we choose an equivalent gap height of $t_{g e}=10 \mu \mathrm{m}$. For these dimensions, driving peak voltage amplitude of approximately $100 \mathrm{~V}$ will yield maximum swing without the plate hitting the substrate. The CMUT with these chosen parameters has a collapse voltage in air $\left(V_{c}\right)$ of $250 \mathrm{~V}$ and in vacuum $\left(V_{r}\right)$ of $820 \mathrm{~V}$. The other equivalent circuit model parameters [32] are $C_{0}=$ $5.4 \mathrm{pF}, L_{R m}=0.58 \mu \mathrm{H}$, and $C_{R m}=7.2 \mu \mathrm{F}$.

\section{B. Array Design}

For a CMUT array design, in general, it is essential to study mutual or self-impedance of elements in an array [37]. The elements in an array are coupled at the acoustic terminals through an impedance matrix. The equivalent circuit model (Fig. 2) is combined with an appropriate impedance matrix. For a $2 \times 2$ array, the equivalent circuit model was simulated 


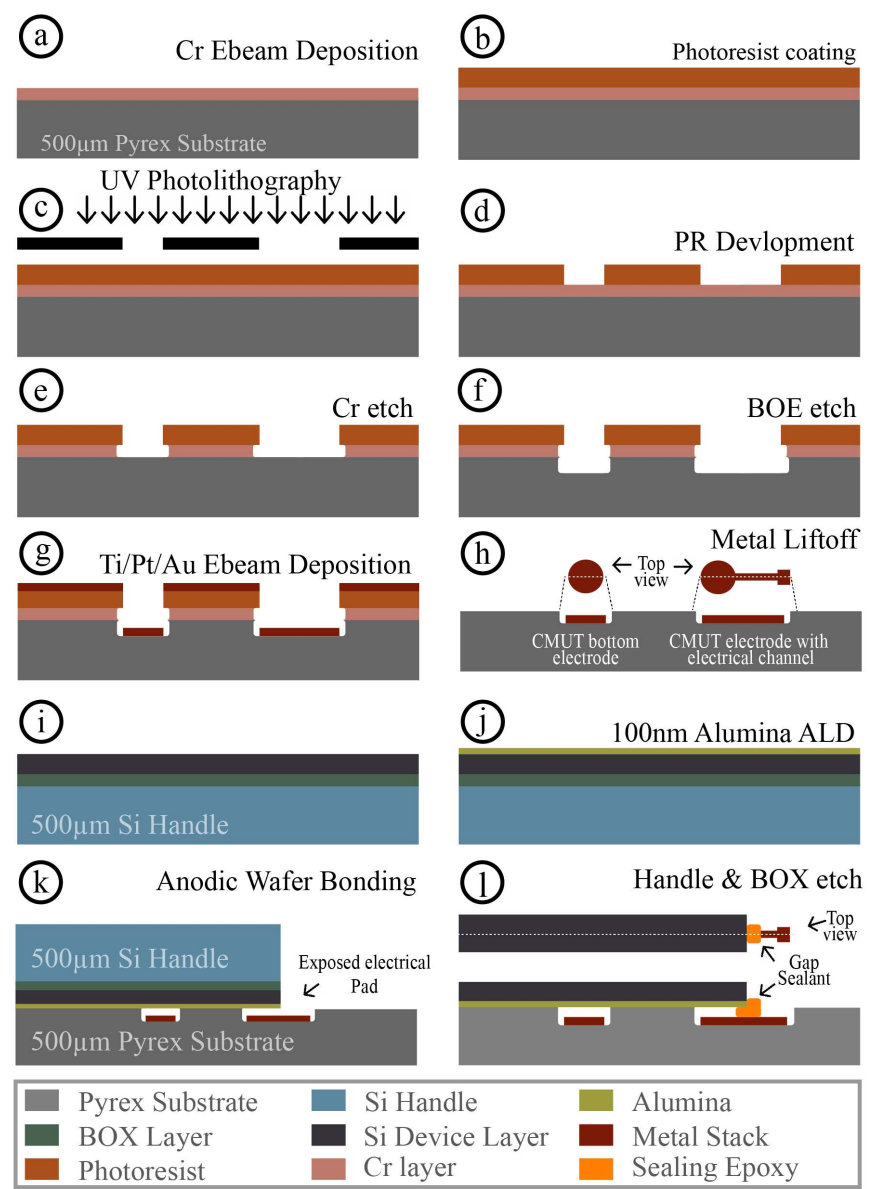

Fig. 3. Cross-section of the process flow for CMUT fabrication: (a) $\mathrm{Cr}$ deposition on Pyrex wafer; (b) PR spin coat; (c) Photolithography; (d) PR development; (e) Cr etch; (f) BOE etch to open cavities; (g) Metal Deposition; (h) Metal Liftoff; (i) Initial SOI wafer; (j) ALD Alumina deposition; (k) Anodic wafer bonding of SOI and Pyrex wafer; (1) Handle and BOX layer etch.

in ADS (Advanced Digital Systems, Keysight Technologies, Santa Rosa, CA), terminated by this impedance matrix [37]. The mutual impedance effects on the array performance were found to be insignificant. This is expected since the acoustic impedance of air is very small compared to the mechanical branch impedance of the CMUT cells with thicker plates and narrower bandwidth.

\section{CMUT FABRICATION}

\section{A. Microfabrication of CMUT Arrays}

CMUT devices can be microfabricated using either wafer bonding or surface micromachining [9], [48], [49]. In our study, the wafer bonding approach is considered more advantageous for the production of the CMUTs that have large diameters and deeper gaps.

The process flow is as follows:

1) Pyrex Substrate Processing: A $30 \mathrm{~nm}$ thick layer of chromium (Cr) is blanket deposited on 100-mm diameter, $500 \mu \mathrm{m}$ thick Pyrex using e-beam evaporation (Fig. 3a). $\mathrm{Cr}$ layer is used as an adhesion layer between the photoresists and Pyrex surface and as a hard mask for a subsequent extended wet buffered oxide etch (BOE 7:1).

Standard photolithography for the only mask is implemented by using $8 \mu \mathrm{m}$ thick photoresist (AZ4562,

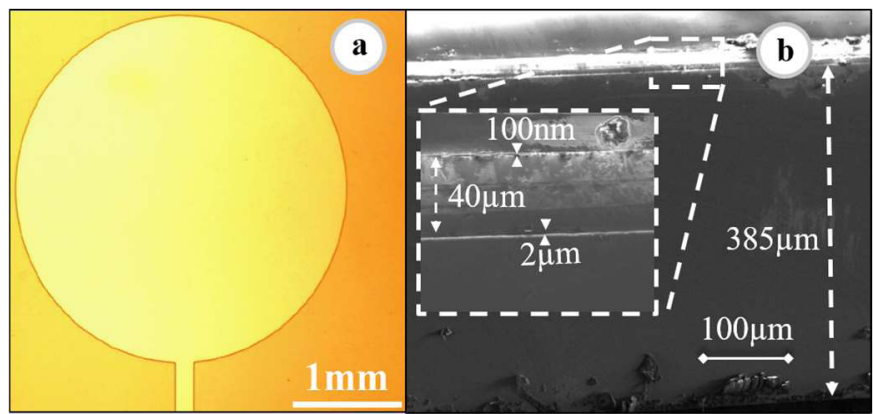

Fig. 4. (a) Optical Image of a single CMUT element imaged through transparent Pyrex substrate, (b) Cross-sectional SEM of SOI wafer with close up of thin layers in the in-picture.

MicroChemicals GmbH, Germany) (Fig. $3 b$ and c). After photoresist development and hard bake (Fig. 3d), the Pyrex wafer is dipped into wet $\mathrm{Cr}$ etchant (TechniEtch Cr01, MicroChemicals $\mathrm{GmbH}$, Germany) to create openings on the $\mathrm{Cr}$ film (Fig. 3e). The wafer is then immersed into BOE solution for 8.5 hours to achieve an etch depth of $10.25 \mu \mathrm{m}$ to form the gap of the CMUT array devices (Fig. 3f). Long wet etch process extended radius $a$ by $25 \pm 2 \mu \mathrm{m}$ that was verified using stylus profilometer (Dektak XT, Bruker Nano Surfaces Division, Tucson, AZ, USA) and optical measurements.

A metal stack of Ti/Pt/Au $(100 \mathrm{~nm} / 100 \mathrm{~nm} / 50 \mathrm{~nm})$ is deposited using e-beam evaporation (Fig. $3 \mathrm{~g}$ ). Ti and Pt film combination is used as a getter material combination [50] during anodic wafer bonding.

A piranha solution is used to etch the hardened photoresist for lifting off the Ti/Pt/Au layers. The remaining Ti/Pt/Au metal stack inside the etched gap regions acts as the bottom electrode of the CMUT devices (Fig. 3h). Cr etchant is then used to remove $\mathrm{Cr}$ from the entire Pyrex wafer surface. Fig. 4a shows an optical image of a single CMUT element imaged through the transparent Pyrex substrate.

2) Silicon-on-Insulator (SOI) substrate processing: 100-mm diameter, highly doped, SOI (P-type (B), device resistivity $<0.0015 \Omega \mathrm{cm}$, Ultrasil Corp, USA) wafers with $40 \mu \mathrm{m} \pm 0.5 \mu \mathrm{m}$ thickness of Si device layer, $2 \mu \mathrm{m} \pm$ $5 \%$ thickness of buried oxide (BOX) layer and $385 \mu \mathrm{m} \pm$ $15 \mu \mathrm{m}$ thickness of handle layer (Fig. 3i) are chosen. $100 \mathrm{~nm}$ thick alumina layer $\left(\mathrm{Al}_{2} \mathrm{O}_{3}\right.$-Insulator layer) is deposited on the device side of the SOI wafer using a thermal atomic layer deposition (ALD- Savannah, Cambridge Nanotech Inc., USA) process (Fig. 3j). Fig. 4b shows a cross-sectional SEM image of the SOI wafer.

To check the surface quality, an AFM (MFP-3D, Oxford Instruments Asylum Research Inc. Santa Barbara, CA, USA) measurement on the alumina surface is performed. The measurement showed that the average surface roughness of the alumina coated surface is $0.2 \mathrm{~nm}$. Pyrex and SOI wafers are bonded to each other by using an anodic wafer bonding service (EV Group E. Thallner $\mathrm{GmbH}$, Austria) (Fig. 3k).

3) Post-Processing: After the bonding process, all the CMUT gaps, and a significant portion of the metal stack used for electrical wiring and base electrode formation, is under the ALD alumina coated SOI wafer. The electrical connection pads of the individual CMUT array elements are kept 


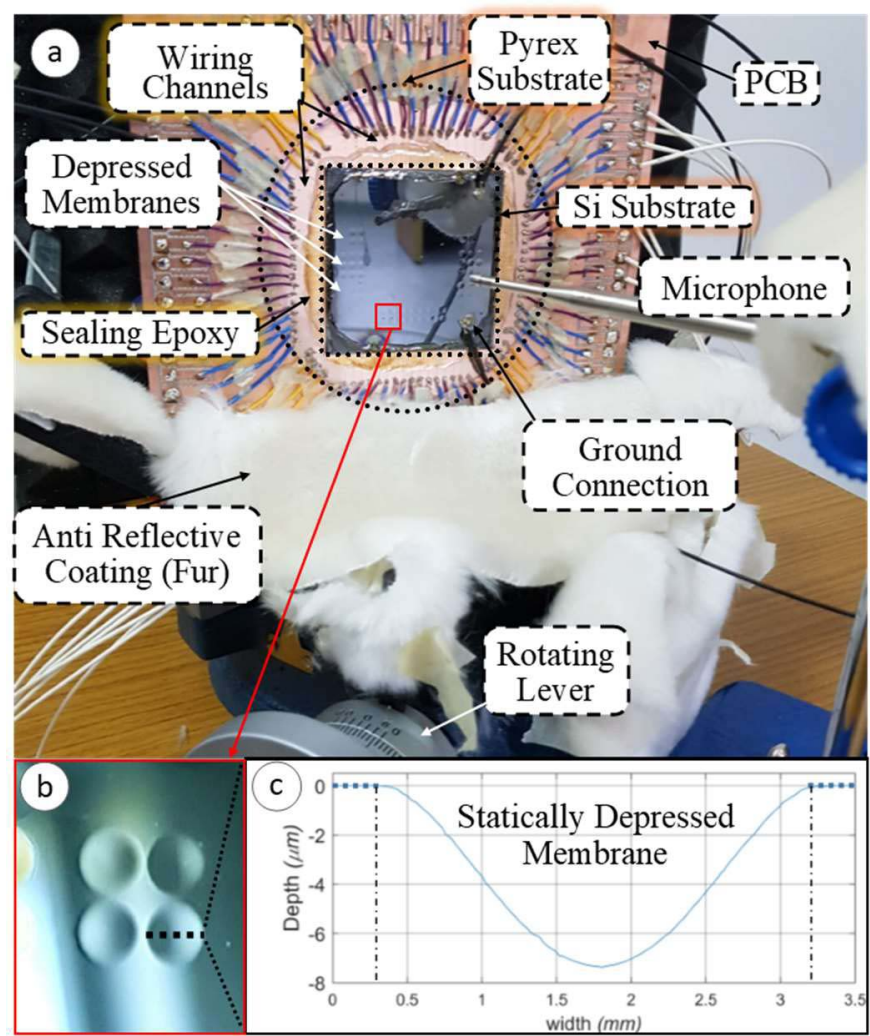

Fig. 5. (a) CMUT array mounted onto a rotating stage. The stage as well as the microphone mounting stand are covered in ARC to absorb reflections. Both microphone and substrate are placed farther away to avoid reflecting planes. (b) Close up image of a CMUT array displaying depressed CMUT membranes. (c) Stylus profile of a statically depressed CMUT membrane.

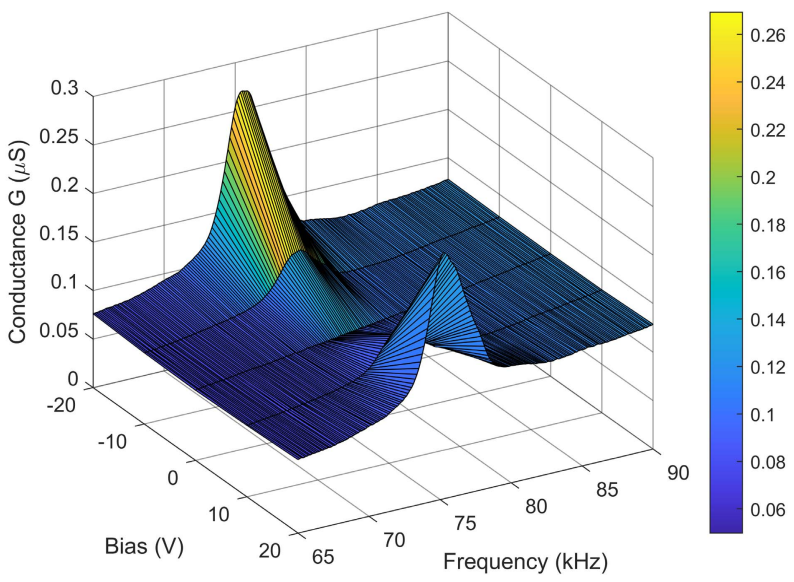

Fig. 6. Impedance measurement of a single CMUT with frequency and bias sweep.

outside the SOI wafer to allow external electrical connections (Fig 5). As the gaps are still at atmospheric pressure, the channels inside the Pyrex wafers need to be vacuum sealed (Fig. 3k).

The entrances of the wiring channels are manually sealed using a low viscosity epoxy resin (Biresin CR120 epoxy-resin \& CH120 Hardener, Sika, Baar, Switzerland). The wafers are then placed into a vacuum chamber for over 15 hours to remove air from the cavities while partially curing the low

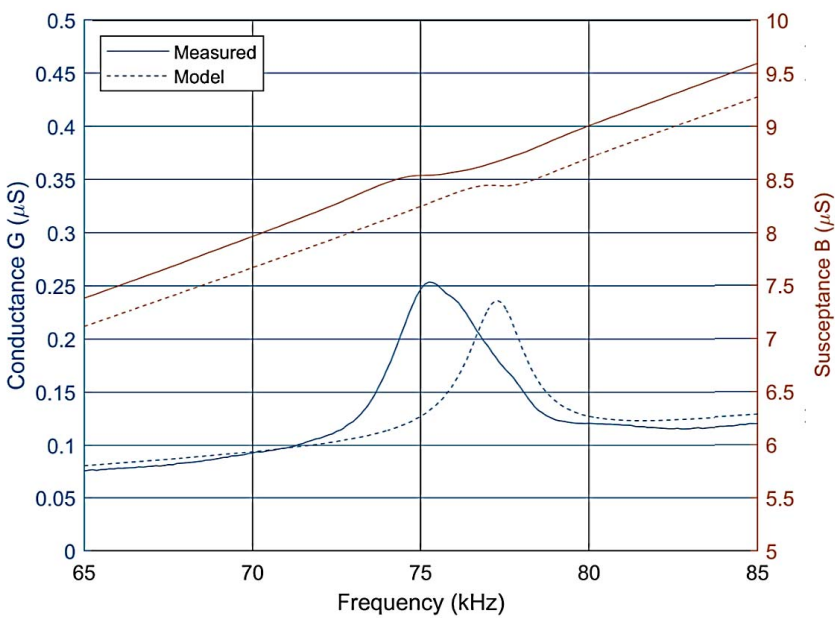

Fig. 7. Measured and model-predicted response for conductance and susceptance curves of a single CMUT element.

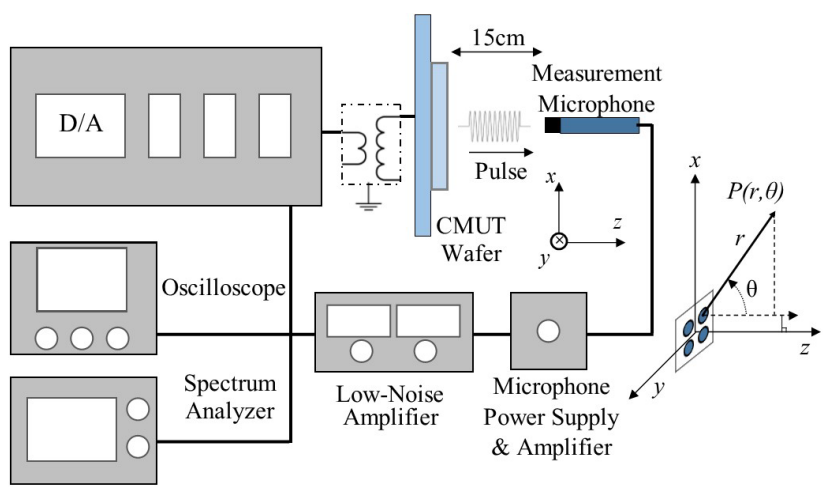

Fig. 8. Block diagram for pressure measurements of a CMUT transmit array. CMUT array is placed in a rigid baffle. Measurements are performed in $x-z$ plane. In far field, $\theta$ for an element becomes congruent to that of an array.

viscosity epoxy resin. After the gaps beneath the radiation plates are vacuumed, the wafers are immediately transferred to an oven for hard curing of the epoxy at $120^{\circ} \mathrm{C}$ for 6 hours (Fig. 31).

A donut-shaped shadow mask is attached to the top of the Pyrex substrate to mask the exposed electrodes, leaving only the handle layer of the SOI wafer available for Si reactive ion etching (RIE). $\mathrm{SF}_{6}$ and Ar based RIE recipe was used in an ICP chamber (ICP615, Surface Technology Systems, UK) to isotropically dry etch the handle layer. After removal of the handle layer, $2 \mu \mathrm{m}$ thick BOX layer is wet etched using BOE to reveal the device layer of the SOI wafer which forms the vibrating plates of the CMUT array devices (Fig. 31). Stylus profilometer measurements are carried out on all elements and $7 \mu \mathrm{m}$ depression $\left(X_{P}\right)$, at the central point of each CMUT plate across the wafer is observed (Fig. 5 b-c). This measurement is consistent with our calculations, which is an indication of a good vacuum seal.

A PCB is used to take out the electrical connections from the Pyrex wafer (Fig. 5a). Among four of the $2 \times 2$ CMUT arrays fabricated on a wafer, all elements in two of the CMUT arrays were able to generate pressure, while the other two 


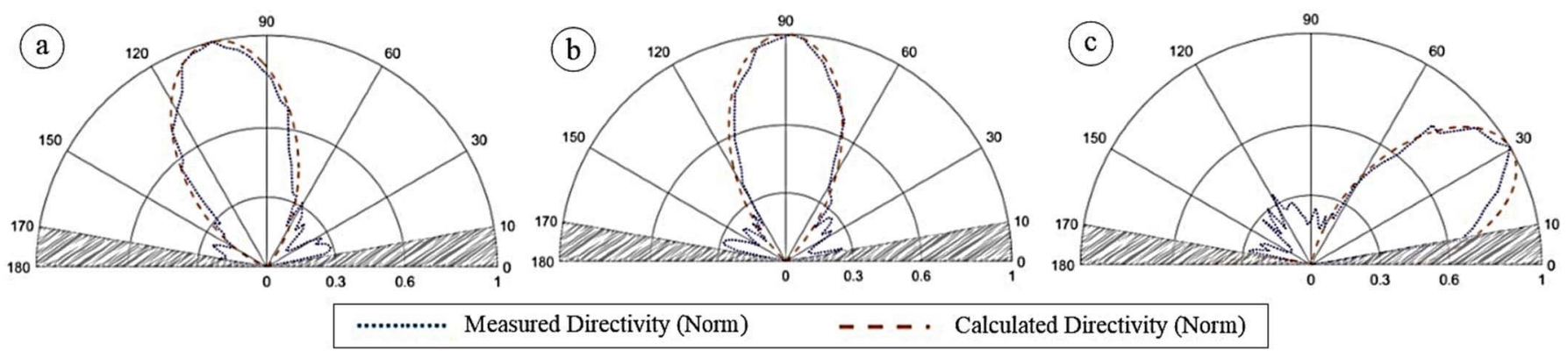

Fig. 9. Calculated and measured directivity (normalized) for a $2 \times 2$ CMUT array in the $x-z$ plane. (a) beam steered at $105^{\circ}$, (b) $90^{\circ}$ and (c) $30^{\circ}$ with respect to the surface of CMUT array.

CMUT arrays had at least one element non-operational after the bonding process.

\section{B. Design Validation}

The CMUT cells are characterized using an impedance analyzer (HP4194A, Hewlett-Packard, Palo Alto, CA). The measurement is performed by sweeping bias voltage from $-20 \mathrm{~V}$ to $20 \mathrm{~V}$ at an $a c$ drive of $0.5 \mathrm{~V}$ in a long integration mode. Fig. 6 shows an impedance measurement of a CMUT element with symmetry around zero bias. This behavior indicates that the amount of charging on the CMUT radiation plate is insignificant [51]. The unbiased operation is not possible if the insulator layer is charged. On the other hand, the unbiased operation does not induce charging in the insulator, since the electric field is alternating. A slightly lower resonant frequency and an increased bandwidth in comparison to the model's predicted response is observed. A similar conductance response with a $2 \%$ dispersion in resonance frequency is observed among 35 out of 45 elements, which were operational after the fabrication.

The variations in the radius of the gap due to extended BOE etch lowers the resonance frequency by $1.8 \%$ on the average with some dispersion. Furthermore, the vibration of the radiation plates excites waves in the silicon plate at the clamped edge, and in the substrate [33]. This energy manifests itself as loss and contributes to the enlargement of the bandwidth. Energy loss due to trapped air in the gap is not expected to be significant. The static depression of the plate in each cell, depicted in Fig. 5(c), are in agreement with the design requirement, which verifies that the vacuum seal is good.

The calculated quality factor together with measured conductance peaks can be used to account for losses in the elements [33]. With $r_{\text {loss }}=2.21 \pi a^{2} \rho_{0} c_{0}, C_{P}=1.76 C_{0}$, a loss tangent of 0.00014 , and a very large $Z_{B}$, we were able to match the model results with the measurement results [33] closely as shown in Fig. 7.

FEA for a single CMUT cell was also performed to determine the resonance frequency (Trans126 is used as single CMUT transducer material to perform modal analysis to extract $f_{r}$ in ANSYS v.14.5, ANSYS Inc., Canonsburg, PA). The obtained response is very close to circuit modeling and measured CMUTs (Table II).
TABLE II

Resonance Frequency Obtained via Circuit Modelling, FEA AND MEASUREMENT

\begin{tabular}{cccc}
\hline \hline & Circuit Model & FEA & $\begin{array}{c}\text { Measurement } \\
\text { (Avg.) }\end{array}$ \\
\cline { 2 - 4 } $\begin{array}{c}\text { Resonance } \\
\text { Frequency }\left(f_{r}\right)\end{array}$ & $77.6 \mathrm{kHz}$ & $77 \mathrm{kHz}$ & $76 \mathrm{kHz}$ \\
\hline \hline
\end{tabular}

\section{Performance Evaluation}

\section{A. Pressure and Directivity Calculation}

Pressure field, $p$, for a clamped plate CMUT array, with $N$ elements, located on an infinite rigid baffle, can be calculated using the equation [37]

$$
p(r, \theta, \varphi)=j \frac{\rho_{m} c_{0} k_{r} \pi a^{2}}{2 \pi} D(\theta) \sum_{i=1}^{N} U_{R_{i}} \frac{e^{-j k_{r} r_{i}}}{r_{i}}
$$

where,

$$
\mathrm{D}(\theta)=\frac{48 \mathrm{~J}_{3}\left(\mathrm{k}_{\mathrm{r}} \mathrm{a} \sin \theta\right)}{\left(\mathrm{k}_{\mathrm{r}} \mathrm{a} \sin \theta\right)^{3}}
$$

is the pressure directivity pattern of a CMUT cell [52]. Here $\mathrm{J}_{3}$ is the Bessel function of the $3^{\text {rd }}$ kind, $U_{R i}$ is the $r m s$ velocity phasor at the surface of the $i^{t h}$ cell and $r_{i}$ is the radial distance of the element to the observation point in a medium. The pressure for a single element measured at a specific distance can be used to calculate the pressure at the surface of the transducer.

As the measurements are taken in the $x-z$ plane, $\varphi$ becomes zero. In far field of the array, $\theta$, for a single element CMUT becomes congruent to that of an array (Fig. 8). For a $2 \times 2$ array, directivity pattern, $D_{p}(\theta)$, can be written as [53],

$$
D_{p}(\theta)=\frac{\sin \left\{\left(k_{r} d\right) \sin \theta\right\}}{4 \sin \left\{\left(k_{r} d / 2\right) \sin \theta\right\}}
$$

Dashed lines in Fig. 9 show normalized directivity patterns calculated using the design parameters in Table I.

\section{B. Array Compensation and Measurements}

Due to the dispersion in resonance frequencies, not all of the array elements can be operated at the same frequency to obtain maximum pressure. For beam steering, it is crucial to have the same amount of pressure with controlled phase radiated from each element in an array. Hence a compensation is necessary 


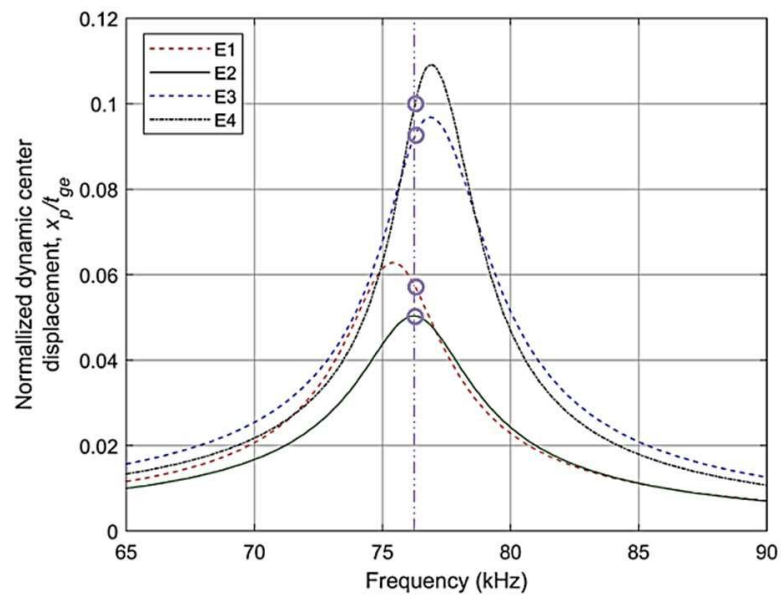

Fig. 10. Calculated normalized peak center displacement deflection using circuit model at $V_{m} / V_{r}=0.06$ for different elements of an array under SAP. To equalize the displacement amplitude for an array, the drive voltages for higher displacement amplitude elements at $76 \mathrm{kHz}$ need to be reduced.

for both phase and amplitude of the output pressure of CMUT elements in an array. Equalization of displacement amplitude is possible if each of the elements is driven using a different drive voltage with an appropriate phase (Fig. 10).

A set of measurements are performed to measure rms pressure of each CMUT element to produce a calibration curve. The CMUT elements are individually driven using a multichannel digital-to-analog (D/A) converter (PXI-6733 card, NI PXIe-1073 Chassis, National Instruments, USA) in pulsed configuration (Fig. 8) with $4 \mathrm{~ms}$ long pulse and $1 \mathrm{~s}$ repetition rate. A measurement microphone (pressure-field microphone, B\&K 4138, Bruel and Kjaer, Naerum, Denmark) is used to measure the radiated pressure. The dynamic range $(3 \%$ THD) of this microphone is between $52.2 \mathrm{~dB}$ and $168 \mathrm{~dB}$ SPL [54], [55], the upper limit of which is well above the measured pressure levels in this work. The microphone is mounted on a preamplifier (B\&K 2633, Bruel and Kjaer, Naerum, Denmark) using an adaptor (B\&K UA 160, Bruel and Kjaer, Naerum, Denmark) and placed at the principal axis of the array at $15 \mathrm{~cm}$ distance. The microphone output is fed to a low noise amplifier $(10-100 \mathrm{kHz}$ bandpass filter with $6 \mathrm{~dB}$ roll-off, SR560, Stanford Research Systems, Sunnyvale, CA). The measurements were recorded in a laboratory environment where the relative humidity of $52 \%$ and temperature of $20^{\circ} \mathrm{C}$ was observed throughout the whole measurement process. The output pressure is measured separately using D/A, spectrum analyzer (HP85901, Hewlett-Packard, Palo Alto, CA), and oscilloscope (DSO1002A, Agilent, Keysight Technologies, USA). The rms pressure for a time signal obtained using an oscilloscope is estimated from the amplitude at the latter part of the long pulse waveform after the transients are decayed (Fig. 11).

To compensate for phase variation between the elements, we excited two elements simultaneously at the same frequency and at their respective drive voltages required for a given pressure amplitude. The output pressure is maximized as one of the element's phase is adjusted (up to $0.16 \pi$ radians). The element

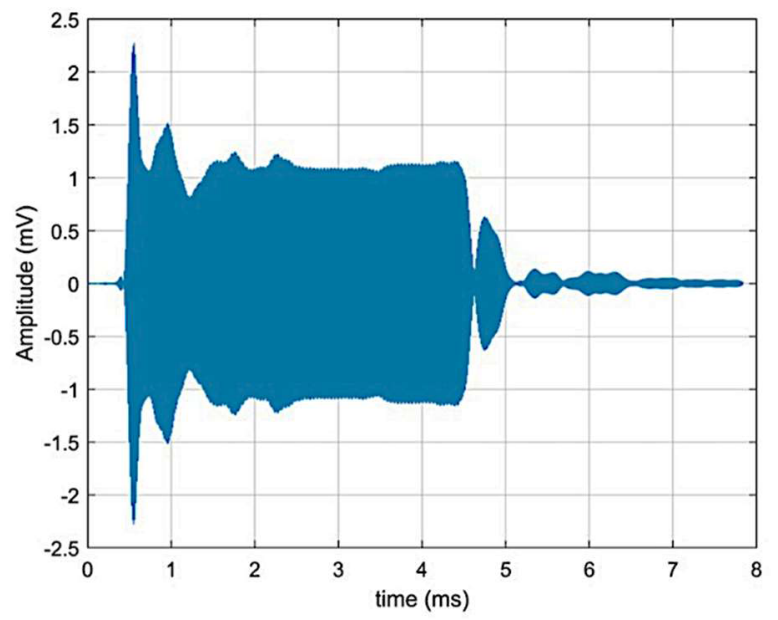

Fig. 11. A long pulse transmitted using a $2 \times 2$ CMUT array at $76 \mathrm{kHz}$.

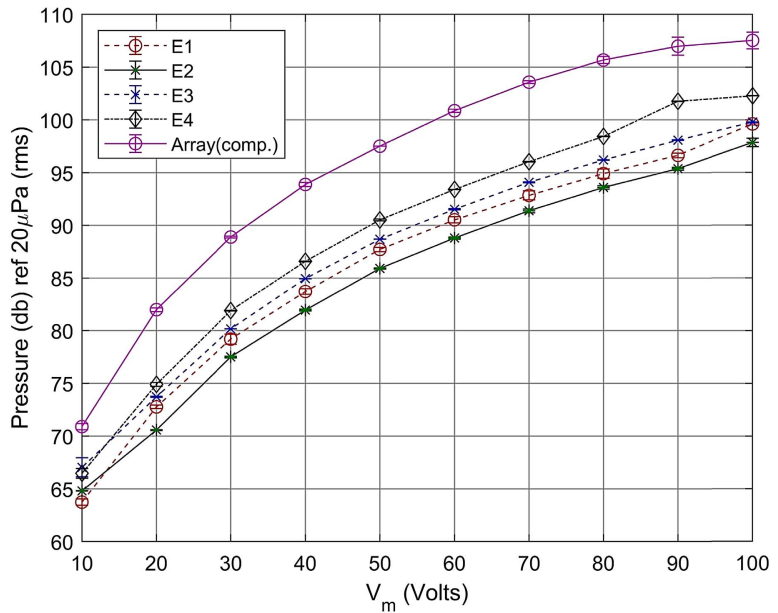

Fig. 12. Mean of pressure measurements at a distance of $15 \mathrm{~cm}$ for a $2 \times 2$ compensated array and its elements driven at $75.8 \mathrm{kHz}, 76 \mathrm{kHz}$, and $77.6 \mathrm{kHz}$ on the array axis obtained by a measurement microphone. The parallel bars show the standard deviation of pressure variation at different frequencies, which is very low below $80 \mathrm{~V}$.

pressure levels are used as a calibration to obtain equalized element output pressures necessary for compensation of array. In Fig. 12, the horizontal axis is respective drive voltage amplitudes for each element in element pressure measurements. In array mode, the horizontal axis represents drive voltage amplitude of E2 for compensated array pressure measurement while other elements in array pressure measurement are driven by their respective compensated voltage amplitude and phases. By matching each element pressure and phases in this manner, we were able to obtain an array pressure that is $11 \mathrm{~dB}$ higher than its least sensitive element of the four-element array.

\section{Beam Steering a CMUT Array}

For beam steering, the required excitation phase delay was calculated using a phased array geometry [56] for each of the elements in the array. In this study, elements were driven with a phase delay to steer the beam at $30^{\circ}, 90^{\circ}$, and $105^{\circ}$. 


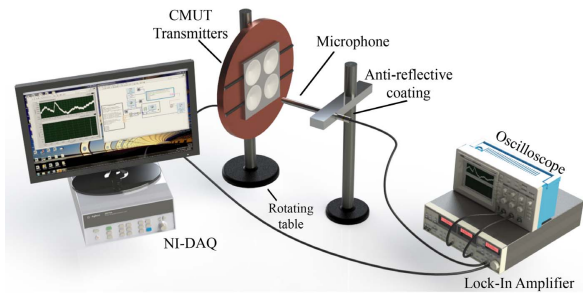

Fig. 13. Measurement setup for an airborne CMUT array for beam steering measurements. The distance from the microphone to the CMUT is $15 \mathrm{~cm}$. All surrounding surfaces around the setup are covered with anti-reflective coatings to avoid reflections during the measurements.

TABLE III

Comparison Between Selected Airborne Ultrasonic Phased ARray PERFormanCES

\begin{tabular}{|c|c|c|c|c|c|c|}
\hline Ref. & Type & $\begin{array}{c}\text { Primary } \\
\text { functionality }\end{array}$ & Pressure & $\begin{array}{c}f_{r} \\
(\mathrm{kHz})\end{array}$ & $\begin{array}{l}\text { Drive } \\
(\mathrm{V})\end{array}$ & $\begin{array}{c}\text { Aperture }\left(\mathrm{mm}^{2}\right) \\
\text { Elements }(\mathrm{N})\end{array}$ \\
\hline [1] & $\begin{array}{l}\text { Ferro- } \\
\text { electric }\end{array}$ & $\begin{array}{l}\text { Beam } \\
\text { steering }\end{array}$ & $\begin{array}{c}102 \mathrm{~dB} @ \\
20 \mathrm{~cm}_{\text {focus }} \mathrm{a}\end{array}$ & 100 & $400 \mathrm{~V}_{\mathrm{ac}}$ & $\begin{array}{c}109 \times 34 \\
32 \text { element }\end{array}$ \\
\hline [2] & $\begin{array}{l}\text { Piezo- } \\
\text { electric }\end{array}$ & $\begin{array}{l}\text { Beam } \\
\text { steering }\end{array}$ & $\begin{array}{l}132 \mathrm{~dB}^{\mathrm{b}} \\
\text { @a) } 30 \mathrm{~cm}\end{array}$ & 30 & $4 \mathrm{~V}$ & $\begin{array}{c}70 \times 54 \\
8 \text { element }\end{array}$ \\
\hline$[17]$ & CMUT & $\begin{array}{c}\text { Parametric } \\
\text { array }\end{array}$ & $\begin{array}{l}135 \mathrm{~dB} \\
\text { surface } \\
\text { pressure }\end{array}$ & 50 & $\begin{array}{l}380 \mathrm{~V}_{\mathrm{dc}} \\
200 \mathrm{~V}_{\mathrm{ac}}\end{array}$ & $\begin{array}{c}2 \text { quadrants of } \\
100 \text { mm wafer }^{\mathrm{c}} \\
\begin{array}{c}35 \text { of } 71 \\
\text { elements }\end{array} \\
\end{array}$ \\
\hline $\begin{array}{l}\text { This } \\
\text { Study }\end{array}$ & CMUT & $\begin{array}{l}\text { Beam } \\
\text { steering }\end{array}$ & $\begin{array}{c}144 \mathrm{~dB} \\
\text { surface } \\
\text { pressure }\end{array}$ & 77 & $\begin{array}{r}0 \mathrm{~V}_{\mathrm{dc}} \\
100 \mathrm{~V}_{\mathrm{ac}}\end{array}$ & $\begin{array}{c}6 \times 6 \\
4 \text { elements }\end{array}$ \\
\hline
\end{tabular}

${ }^{\mathrm{a}}$ Near field measurement made using all elements driven together at focus.

${ }^{\mathrm{b}} 140-145 \mathrm{~dB}$ estimated surface pressure.

${ }^{\mathrm{c}}$ Element pitch is not reported making it difficult to calculate the actual aperture.

The CMUT array is operated in a continuous wave excitation mode. A lock-in amplifier (SR850, Stanford Research Systems, Sunnyvale, CA) is used with a time constant of $100 \mathrm{~ms}$ and roll-off of $12 \mathrm{~dB} /$ octave. A reference signal of similar amplitude and frequency is also provided to the setup. A fur is used at all surrounding reflective surfaces to reduce acoustic interference (Fig. 5). The CMUT wafer is erected vertically on top of a $360^{\circ}$ stage (Fig. 13). The stage is manually rotated from $10^{\circ}$ to $170^{\circ}$ with $3^{\circ}$ steps.

Dotted lines in Fig. 9 show normalized directivity pressure measurement at $76 \mathrm{kHz}$. The beam pattern was symmetric on the central axis. For beam steered at $30^{\circ}, 90^{\circ}$ and $105^{\circ}$, the calculations are consistent with the measured beam pattern within measurement tolerances.

\section{Discussions}

Various airborne ultrasonic transmitting transducers capable of producing high pressure or beamforming and steering capability are summarized in Table III. This study presents a CMUT array that is capable of producing high pressure (144 dB at the surface of the transducer), which is higher than the pressures reported in the literature. Furthermore, the compensated array is beam steered in a precise manner. The compensation requirement remains constant for the entire drive range, which makes the array usable in applications where beam steering is required at high-pressure levels. In comparison to our design, other devices are driven at higher drive voltages.

\section{CONCLUSION}

We presented the design, microfabrication, and measurement of an airborne CMUT transmit array that produces high intensity, beam steerable ultrasound. The CMUTs were produced using an integrated fabrication method that involved a single lithographic process.

We achieved high transmission pressure using only ac drive, as we drive the CMUTs at half the operation frequency. We demonstrated that we can predict the performance of fabricated CMUTs. CMUT elements operate such that the plate movement covers the entire gap, hence providing the maximum pressure. For a single CMUT element, we experimentally obtained a maximum pressure of $144 \mathrm{~dB}$ at the surface of the transducer. A $2 \times 2$ compensated CMUT array produced $11 \mathrm{~dB}$ higher pressure than the least sensitive element of the CMUT array.

Fabrication inaccuracies are inevitable in a multiuser cleanroom facility. Dry etching may be used to generate Pyrex cavities to lower variation in lateral dimensions. Making the fabrication process more efficient can reduce the discrepancies between the elements, which both reduces the compensation requirements and increases the amount of radiated pressure of an array. With the processes optimized for industrial fabrication facilities, the elements of the array will be almost identical, in which case the same amount of pressure can be produced using $40 \mathrm{~V}$ amplitude. Employing a more efficient electrical routing on the wafer, and usage of smaller die spaces with narrower or shorter electrode connections, can help to reduce the parasitic capacitance. A microfabrication process can be used to produce larger arrays that can be operated in unison with cascaded phased array drivers.

\section{ACKNOWLEDGMENT}

The authors would like to thank Semih Bozkurt for his help with AFM measurements.

\section{REFERENCES}

[1] J. L. Ealo, J. J. Camacho, and C. Fritsch, "Airborne ultrasonic phased arrays using ferroelectrets: A new fabrication approach," IEEE Trans. Ultrason., Ferroelectr., Freq. Control, vol. 56, no. 4, pp. 848-858, Apr. 2009.

[2] J. Yamamoto, Y. Mizuno, M. Tabaru, and K. Nakamura, "Linear array transducer for high-power airborne ultrasound using flextensional structure," Jpn. J. Appl. Phys., vol. 54, no. 7S1, Jul. 2015, Art. no. 07 HE16.

[3] B. T. Khuri-Yakub et al., "Silicon micromachined ultrasonic transducers," Jpn. J. Appl. Phys., vol. 39, no. 5, pp. 2883-2887, 2000.

[4] K. Brenner, A. S. Ergun, K. Firouzi, M. F. Rasmussen, Q. Stedman, and B. Khuri-Yakub, "Advances in capacitive micromachined ultrasonic transducers," Micromachines, vol. 10, no. 2, p. 152, 2019.

[5] H. T. Soh, I. Ladabaum, A. Atalar, C. F. Quate, and B. T. Khuri-Yakub, "Silicon micromachined ultrasonic immersion transducers," Appl. Phys. Lett., vol. 69, no. 24, pp. 3674-3676, Dec. 1996.

[6] A. S. Logan, L. L. P. Wong, A. I. H. Chen, and J. T. W. Yeow, "A $32 \times 32$ element row-column addressed capacitive micromachined ultrasonic transducer," IEEE Trans. Ultrason., Ferroelectr., Freq. Control, vol. 58, no. 6, pp. 1266-1271, Jun. 2011.

[7] N. Apte, K. K. Park, A. Nikoozadeh, and B. T. Khuri-Yakub, "Bandwidth and sensitivity optimization in CMUTs for airborne applications," in Proc. IEEE Int. Ultrason. Symp., Sep. 2014, pp. 166-169. 
[8] M. S. Salim, M. F. Abd Malek, R. B. W. Heng, K. M. Juni, and N. Sabri, "Capacitive micromachined ultrasonic transducers: Technology and application," J. Med. Ultrasound, vol. 20, no. 1, pp. 8-31, Mar. 2012.

[9] O. J. Adelegan, Z. A. Coutant, X. Zhang, F. Y. Yamaner, and O. Oralkan, "Fabrication of 2D capacitive micromachined ultrasonic transducer (CMUT) arrays on insulating substrates with through-wafer interconnects using sacrificial release process," J. Microelectromech. Syst., vol. 29, no. 4, pp. 553-561, Aug. 2020.

[10] B. Ma, K. Firouzi, K. Brenner, and B. T. Khuri-Yakub, "Wide bandwidth and low driving voltage vented CMUTs for airborne applications," IEEE Trans. Ultrason., Ferroelectr., Freq. Control, vol. 66, no. 11, pp. 1777-1785, Nov. 2019.

[11] J. Joseph, S. G. Singh, and S. R. K. Vanjari, "Fabrication and characterization of SU-8-based capacitive micromachined ultrasonic transducer for airborne applications," J. Micro/Nanolithography, MEMS, MOEMS, vol. 17, no. 1, p. 1, Feb. 2018

[12] H. Nan et al., "Non-contact thermoacoustic detection of embedded targets using airborne-capacitive micromachined ultrasonic transducers," Appl. Phys. Lett., vol. 106, no. 8, Feb. 2015, Art. no. 084101.

[13] N. Apte, B. T. Khuri-Yakub, and K. K. Park, "Capacitive micromachined ultrasound transducers with pressurized cavities," U.S. Patent 9586233 B2, Mar. 7, 2017.

[14] I. O. Wygant et al., "Capacitive micromachined ultrasonic transducers for generation of highly directional sound with a parametric array," J. Acoust. Soc. Amer., vol. 123, no. 5, p. 3375, May 2008.

[15] S. Na, A. I. H. Chen, L. L. P. Wong, Z. Li, M. Macecek, and J. T. W. Yeow, "Capacitive micromachined ultrasonic transducers based on annular cell geometry for air-coupled applications," Ultrasonics, vol. 71, pp. 152-160, Sep. 2016.

[16] G. Allevato et al., "Real-time 3D imaging using an air-coupled ultrasonic phased-array," IEEE Trans. Ultrason., Ferroelectr., Freq. Control, early access, Jun. 26, 2020, doi: 10.1109/TUFFC.2020.3005292.

[17] I. O. Wygant et al., "50 kHz capacitive micromachined ultrasonic transducers for generation of highly directional sound with parametric arrays," IEEE Trans. Ultrason., Ferroelectr., Freq. Control, vol. 56, no. 1, pp. 193-203, Jan. 2009.

[18] Autopilot | Tesla. Accessed: Sep. 20, 2020. [Online]. Available: https://www.tesla.com/autopilot

[19] D. Sun, T. F. Lu, A. Zander, and M. Trinkle, "Near field focusing behaviour of airborne ultrasonic phased arrays influenced by airflows," Int. J. Mech. Mechtron. Eng., vol. 10, no. 5, pp. 835-841, 2016.

[20] D. Horsley, "Wave hello to the next interface," IEEE Spectr., vol. 53, no. 12, pp. 46-51, Dec. 2016.

[21] V. G. Chouvardas, M. K. Hatalis, and A. N. Miliou, "Design and simulation of a tactile display based on a CMUT array," Int. J. Electron., vol. 99, no. 10, pp. 1351-1363, Oct. 2012.

[22] A. Marzo, T. Corkett, and B. W. Drinkwater, "Ultraino: An open phasedarray system for narrowband airborne ultrasound transmission," IEEE Trans. Ultrason., Ferroelectr., Freq. Control, vol. 65, no. 1, pp. 102-111, Jan. 2018.

[23] S. Harput, A. Bozkurt, and F. Y. Yamaner, "Ultrasonic phased array device for real-time acoustic imaging in air," in Proc. IEEE Ultrason. Symp., Beijing, China, Nov. 2008, pp. 619-622.

[24] M. J. G. Molgaard, J. M. F. Hansen, M. H. Jakobsen, and E. V. Thomsen, "Sensitivity optimization of wafer bonded gravimetric CMUT sensors," J. Microelectromech. Syst., vol. 27, no. 6, pp. 1089-1096, Dec. 2018.

[25] Y. Lu et al., "Ultrasonic fingerprint sensor using a piezoelectric micromachined ultrasonic transducer array integrated with complementary metal oxide semiconductor electronics," Appl. Phys. Lett., vol. 106, no. 26, Jun. 2015, Art. no. 263503.

[26] T. Dahl, J. L. Ealo, H. J. Bang, S. Holm, and P. Khuri-Yakub, "Applications of airborne ultrasound in human-computer interaction," Ultrasonics, vol. 54, no. 7, pp. 1912-1921, 2014.

[27] A. S. Erguri, Y. Huang, X. Zhuang, O. Oralkan, G. G. Yarahoglu, and B. T. Khuri-Yakub, "Capacitive micromachined ultrasonic transducers: Fabrication technology," IEEE Trans. Ultrason., Ferroelectr., Freq. Control, vol. 52, no. 12, pp. 2242-2258, Dec. 2005.

[28] Z. Zheng et al., "Development of a novel CMUT-based concentric dualelement ultrasonic transducer: Design, fabrication, and characterization," J. Microelectromech. Syst., vol. 27, no. 3, pp. 538-546, Jun. 2018.

[29] Y. Yu et al., "Experimental characterization of an embossed capacitive micromachined ultrasonic transducer cell," Micromachines, vol. 11, no. 2 , p. 217 , Feb. 2020
[30] K. K. Park and B. T. Khuri-Yakub, "3-D airborne ultrasound synthetic aperture imaging based on capacitive micromachined ultrasonic transducers," Ultrasonics, vol. 53, no. 7, pp. 1355-1362, Sep. 2013.

[31] A. Unlugedik, A. Sinan Tasdelen, A. Atalar, and H. Koymen, "Designing efficient CMUT cells for airborne applications," in Proc. IEEE Int Ultrason. Symp., Chicago, IL, USA, Sep. 2014, pp. 2564-2567.

[32] H. Koymen et al., "An improved lumped element nonlinear circuit model for a circular CMUT cell," IEEE Trans. Ultrason., Ferroelectr., Freq. Control, vol. 59, no. 8, pp. 1791-1799, Aug. 2012.

[33] A. Unlugedik, A. Tasdelen, A. Atalar, and H. Koymen, "Designing transmitting CMUT cells for airborne applications," IEEE Trans. Ultrason., Ferroelectr., Freq. Control, vol. 61, no. 11, pp. 1899-1910, Nov. 2014

[34] T. M. Khan, A. S. Tasdelen, M. Yilmaz, A. Atalar, and H. Koymen, "Beam steering in a half-frequency driven airborne CMUT transmitter array," in Proc. IEEE Int. Ultrason. Symp. (IUS), Glasgow, U.K., Oct. 2019, pp. 762-765.

[35] A. Caronti, A. Savoia, G. Caliano, and M. Pappalardo, "Acoustic coupling in capacitive microfabricated ultrasonic transducers: Modeling and experiments," IEEE Trans. Ultrason., Ferroelectr., Freq. Control, vol. 52, no. 12, pp. 2220-2234, Dec. 2005.

[36] K. K. Park, M. Kupnik, H. J. Lee, B. T. Khuri-Yakub, and I. O. Wygant, "Modeling and measuring the effects of mutual impedance on multi-cell CMUT configurations," in Proc. IEEE Int. Ultrason. Symp., San Diego, CA, USA, Oct. 2010, pp. 431-434.

[37] H. K. Oguz, A. Atalar, and H. Koymen, "Equivalent circuit-based analysis of CMUT cell dynamics in arrays," IEEE Trans. Ultrason. Ferroelectr., Freq. Control, vol. 60, no. 5, pp. 1016-1024, May 2013.

[38] F. Y. Yamaner, S. Olcum, H. K. Oguz, A. Bozkurt, H. Koymen, and A. Atalar, "High-power CMUTs: Design and experimental verification," IEEE Trans. Ultrason., Ferroelectr., Freq. Control, vol. 59, no. 6, pp. 1276-1284, Jun. 2012.

[39] H. Koymen, A. Atalar, and A. S. Tasdelen, "Bilateral CMUT cells and arrays: Equivalent circuits, diffraction constants, and substrate impedance," IEEE Trans. Ultrason., Ferroelectr., Freq. Control, vol. 64, no. 2, pp. 414-423, Feb. 2017.

[40] S. Timoshenko and S. W. Woinowsky-Krieger, Theory of Plates And Shells. New York, NY, USA: McGraw-Hill, 1959.

[41] E. Ventsel and T. Krauthammer, Thin Plates and Shells, 1st ed. New York, NY, USA: Marcel Dekker, 2001.

[42] P. J. Holmes and D. A. Rand, "The bifurcations of duffing's equation: An application of catastrophe theory," J. Sound Vibrat., vol. 44, no. 2, pp. 237-253, Jan. 1976.

[43] H. Koymen and A. Atalar, "High performance sealed-gap Capacitive microphone," U.S. Patent 20180302 726, May 7, 2020.

[44] D. H. Johnson and D. E. Dudgeon, Array Signal Processing: Concepts and Techniques, 1st ed. Upper Saddle River, NJ, USA: Prentice-Hall, 1993.

[45] C. A. Balanis, Antenna Theory, Analysis and Design, 3rd ed. Hoboken, NJ, USA: Wiley, 2005.

[46] R. C. S. Cobbold, Foundations of Biomedical Ultrasound, Array Signal Processing: Concepts and Techniques. Oxford, U.K.: Oxford Univ. Press, 2007, pp. 437-441.

[47] G. W. C. Kaye and T. H. Laby. Tables of Physical and Chemical Constants and Some Mathematical Functions, 16th Ed. Accessed: Sep. 20, 202. [Online]. Available: https://web.archive. org/web/20190518022538/http://www.kayelaby.npl.co.uk/toc/

[48] X. Jin, I. Ladabaum, and B. T. Khuri-Yakub, "The microfabrication of capacitive ultrasonic transducers," J. Microelectromech. Syst., vol. 7, no. 3, pp. 295-302, 1998

[49] N. Tas, T. Sonnenberg, H. Jansen, R. Legtenberg, and M. Elwenspoek, "Stiction in surface micromachining," J. Micromech. Microeng., vol. 6, no. 4, pp. 385-397, Dec. 1996.

[50] A. V. Chavan and K. D. Wise, "Batch-processed vacuum-sealed capacitive pressure sensors," J. Microelectromech. Syst., vol. 10, no. 4, pp. 580-588, 2001.

[51] H. Koymen, A. Atalar, S. Guler, I. Koymen, A. S. Tasdelen, and A. Unlugedik, "Unbiased charged circular CMUT microphone: lumpedelement modeling and performance," IEEE Trans. Ultrason., Ferroelectr., Freq. Control, vol. 65, no. 1, pp. 60-71, Jan. 2018.

[52] D. T. Porter, "Self-and mutual-radiation impedance and beam pattern for flexural disks in a rigid plane," J. Acoust. Soc. Amer, vol. 36, no. 6, pp. 1154-1161, 1964.

[53] L. Bjørnø, "Sonar systems," in Applied Underwater Acoustics: Leif Bjørnø. Amsterdam, The Netherlands: Elsevier, 2017, pp. 587-742.

[54] Product Data: 1/8' Pressure-field Microphone-Type 4138, Brüel \& Kjær, Nærum, Denmark, 2008 
[55] Measuring Microphones-BA 7216-15 (Lecture Note). Nærum, Denmark: Brüel \& Kjær, 1999, p. 13.

[56] O. T. Von Ramm and S. W. Smith, "Beam steering with linear arrays," IEEE Trans. Biomed. Eng., vols. BME-30, no. 8, pp. 438-452, Aug. 1983.

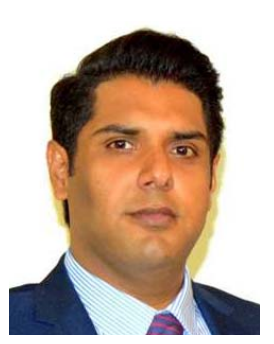

Talha Masood Khan (Student Member, IEEE) received the M.S. degree in electrical engineering from the National University of Sciences and Technology, Islamabad, Pakistan, in 2013. He is currently pursuing the Ph.D. degree with the Institute of Materials Science and Nanotechnology (UNAM), Bilkent University, Ankara, Turkey.

In 2013, he joined the Faculty of the Department of Electrical Engineering, PIET, Multan, Pakistan, as a University Lecturer. He is also a Research and Teaching Assistant with UNAM, Bilkent University. His research interests include Bio-MEMS, MEMS sensors and actuators, airborne acoustics, and ultrasonic transducer design (cMUT).

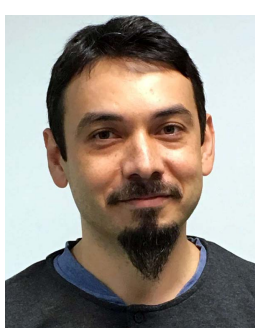

Akif Sinan Taşdelen received the B.S. and M.S. degrees in electrical and electronics engineering from Bilkent University, Ankara, Turkey, in 2004 and 2007, respectively.

In 2008, he joined the Bilkent University Acoustics and Underwater Technologies Research Center (BASTA), where he is currently working as the Chief Technical Research Engineer. His research interests include passive coherent location radar, underwater acoustics, transducer array design, cMUT, capacitive microphones, and biomedical ultrasound.

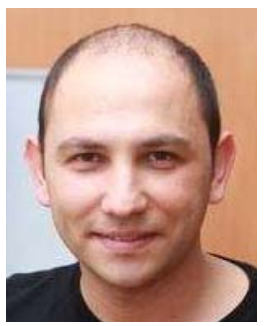

Mehmet Yilmaz received the B.S. degree (Hons.) from the Izmir Institute of Technology, the M.S degree from Koc University, and the Ph.D. degree from Columbia University, all in mechanical engineering.

After his Ph.D. degree studies, he joined IBM Microelectronics Division, Albany Nanotechnology Research and Development Center, New York, NY, USA. During his M.S. and Ph.D. degrees studies, he specialized in the design and microfabrication of MEMS and the integration of MEMS with nanostructures. During his Ph.D. degree studies, he has also specialized in nanomechanical characterization of materials in-situ scanning electron microscope (SEM). During his time at IBM Microelectronics Division, he worked on developing reactive ion etching (RIE) processes via patterning and developing new integration schemes for $10 \mathrm{~nm}$ and $7 \mathrm{~nm}$ technology nodes, and silicon 3D integration technologies. He is currently a principal investigator at the National Nanotechnology Research Center (UNAM), Bilkent University. In spirit, he is an academician, scientist, engineer, inventor, and entrepreneur. He is interested in mechanical characterization, elastic strain engineering, understanding, and tuning the material properties at small length scales for energy and information technology applications, and developing new unit processes and integration processes for batch-compatible nanofabricated, high yield, MEMS and NEMS devices for energy, information technology, and health applications.

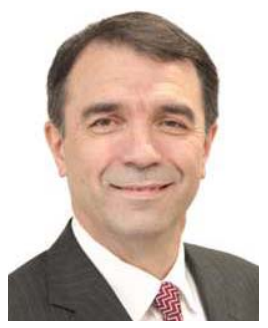

Abdullah Atalar (Fellow, IEEE) received the B.S. degree from Middle East Technical University, Ankara, Turkey, in 1974, and the M.S. and Ph.D degrees from Stanford University, Stanford, CA USA, in 1976 and 1978, respectively, all in electrical engineering.

From 1978 to 1980 , he was first a Post-Doctoral Fellow and later an Engineering Research Associate with Stanford University. For about one year, he worked in Hewlett Packard Labs, Palo Alto, CA, USA. From 1980 to 1986, he was on the faculty of the Middle East Technical University as an Assistant Professor. In 1983, he worked for Ernst Leitz Wetzlar (now Leica), Wetzlar, Germany, on leave from the University. In 1986, he joined Bilkent University as the Chairman of the Electrical and Electronics Engineering Department and served in the founding of the Department, where he is currently a Professor. In 1995, he was a Visiting Professor at Stanford University. From 1996 to 2010, he was the Provost of Bilkent University, where he is currently the Rector. From 2004 and 2011, he has served as a member of the Science Board of TUBITAK. His current research interests include microwave electronics and micromachined sensors.

Dr. Atalar is a member of the Turkish Academy of Sciences since 1997. He was awarded the Science Award of the Turkish Scientific Research Council (TUBITAK) in 1994.

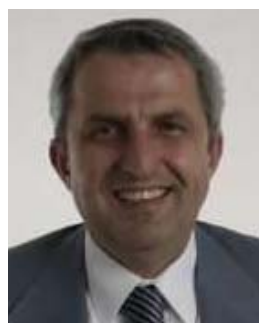

Hayrettin Köymen (Senior Member, IEEE) received the B.Sc. and M.Sc. degrees from the Middle East Technical University (METU), Ankara, Turkey, in 1973 and 1976, respectively, and the Ph.D. degree from Birmingham University, U.K., in 1979, all in electrical engineering.

He worked as a Faculty Member with the Department of Marine Sciences, METU, Mersin, and the Department of Electrical Engineering, METU, Ankara, from 1979 to 1990. In 1990, he joined the faculty of Bilkent University, where he is currently a Professor with the Department of Electrical and Electronics Engineering. His research activities include underwater and airborne acoustic and ultrasonic transducer design, underwater acoustics, underwater and airborne acoustic systems, acoustic microscopy, ultrasonic NDT, biomedical instrumentation, mobile communications, and spectrum management.

Prof. Koymen is a fellow of the IET. 